\title{
High-temperature superconductors change the game
}

\author{
By Arthur L. Robinson \\ Feature Editor James Misewich
}

A quarter century after the Nobel-prize-winning discovery in 1986 of the first "high-temperature superconductors" (HTS), the once heady prospect of transforming the electrical power industry with lossless superconductors operating at liquid nitrogen temperature is no longer a dream. Years of materials research and a suite of highly successful demonstration projects have put HTS not only on the doorstep of the electric power grid but of facilitating its entry into the $21 \mathrm{st}$ century, including the increasingly mandatory shift to green, renewable energy.

The US National Academy of Engineering describes the vast networks of electrification known as the grid as "the greatest engineering achievement of the 20th century." But the future demands better: a grid that is not fragmented but truly national in scope; where large amounts of power can be transported over vast distances in a flash by underground cables from wherever generated to wherever needed; where networks are redundant to back up outages; where overloads, short-circuits, losses, and fluctuations can be instantly compensated; where fleets of electric cars can be plugged into the grid to recharge without overloading it; and where the frequency and voltage of the power are reliably maintained (increasingly essential for the digital society).

Many think the grid is not up to the demands of the $21 \mathrm{st}$ century without a serious effort to upgrade. A 2010 report titled "Science for Energy Technology" from the US Department of Energy's (DOE's) Office of Basic Energy Sciences offers an entrée for high-temperature superconductor power equipment, [but] "to achieve competitive cost-performance, significant improvements over existing wire performance are still required." Surveying current major HTS challenges, the DOE report says, "chief among these [is] a major increase (at least a factor of two) in high-temperature superconducting current-carrying capability under operating conditions."

Superconductors are best known for the lossless transmission of dc electric currents when cooled below their transition temperatures. In service, however, superconductors contain arrays of nanosized, quantized, "flux tubes" or vortices of supercurrent circulating around non-superconducting cores. Vortices are no problem when pinned at structural defects like dislocations or impurities in the superconductor, but at a critical current, they break free, dissipating energy as they move, thereby introducing a resistance. In practice, incorporating pinning defects designed to block vortex motion raises the critical current to levels that are useful, but there is much room for improvement.

Determining the maximum critical current that could be obtained by introducing the "ideal" distribution of defects awaits the ability to understand the behavior of large arrays of vortices in a field of pin sites. In large arrays, the best critical currents are only $\sim 20 \%$ of the theoretical critical current, but why is not known. "There's some theory but still lots of empiricism," said Drew Hazelton of SuperPower, Inc., a major HTS wire maker.

The availability of HTS conductors will be an industry gamechanger said Steve Eckroad of the Electric Power Research Institute (EPRI). Up until now, utilities have relied on a highvoltage, low-current network based on copper for generators, transformers, and urban underground cables (rural overhead lines are usually aluminum). Superconductors with no dc and only small ac losses plus high current density change the equation to lower voltage and higher current. HTS cables have five times the capacity in the same cross-sectional area as conventional copper cables.

One way to exploit this capability is by combining HTS with renewable energy sources for a truly green grid in which remotely generated power from renewable sources could travel to distant consumers over what wind and solar power advocates call "green power superhighways." However, long-distance transmission is not yet a near-term prospect for HTS, owing to the huge capital investment costs and an unproven track record of benefits.

Here is where the ongoing materials research could pay off. Eckroad said, "Our studies suggest that reducing the present cost of the superconductor by a factor of two would bring the cost of 10-GW, 1200-mile-long, superconducting cables to within range of that of conventional overhead lines. Since underground dc cables also offer substantial environmental, siting, and aesthetic benefits over conventional overhead transmission lines, they may become an attractive alternative option in some situations."

Whether cable or something else, every HTS power applica- 


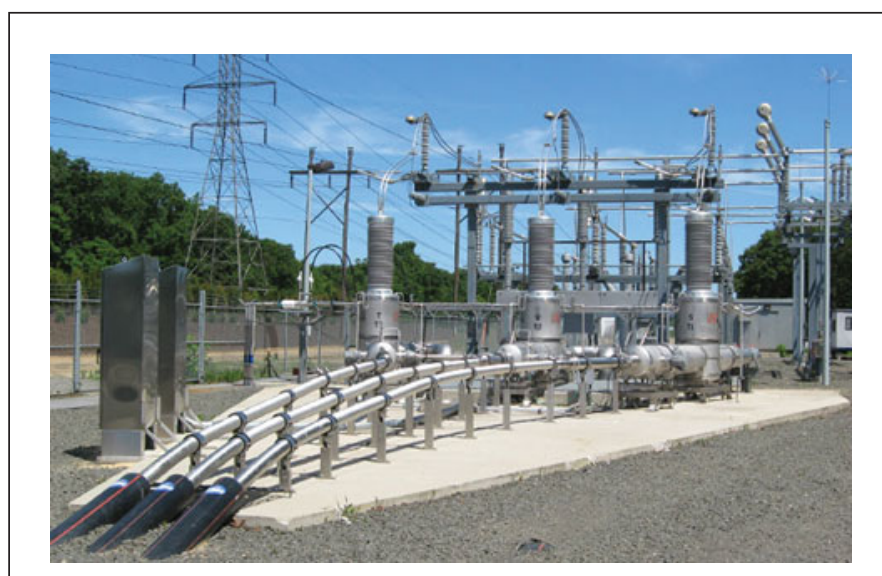

The Long Island Power Authority has been operating, since 2008, a cable system manufactured by Nexans that utilizes AMSC's hightemperature superconductor wire and an Air Liquide cooling system. Energized in April 2008, this is the world's first superconductor transmission voltage cable system, which is capable of transmitting up to $574 \mathrm{MW}$ of electricity and powering 300,000 homes. Photo courtesy of AMSC.

tion begins with composite "wires" in which the superconductor is only one component. Doped bismuth-strontium-calciumcopper-oxygen (BSCCO) compounds emerged as the firstgeneration (1G) HTS material for commercial use. Kilometerlong wires of BSCCO in a silver matrix can now be routinely produced, but since the matrix is $60-70 \%$ of the volume, the wire is inherently costly. Sumitomo Electric Industries remains the principal supplier of $1 \mathrm{G}$ wires.

“Around 1999," said SuperPower's Hazelton, "we looked at the cost projections, and we moved to yttrium-barium-copperoxygen [YBCO]-based second-generation [2G] wires." Other virtues of $2 \mathrm{G}$ conductors include higher current and better performance in high magnetic fields even though the transition temperature is somewhat lower. YBCO conductors take the form of a multilayer tape made from superconductor deposited onto a textured metallic substrate. Two coated-conductor technologies have caught on, one researched at Oak Ridge National Laboratory and commercialized by American Superconductor Corporation (AMSC) and the other developed at Los Alamos National Laboratory and used by SuperPower.

As the demonstration projects suggest, it is largely government support that is helping to grow an HTS industry around the world. Alan Lauder of the Coalition for the Commercial Application of Superconductors estimates that from 1993 through 2011 , DOE offices alone have invested around $\$ 600$ million in the United States to develop HTS technology spanning materials research, wire (or conductor) fabrication, systems assembly (cables, transformers, rotating machinery), and demonstration projects involving utilities aimed at establishing the technical readiness of HTS systems. "The DOE investment has brought HTS technology a long way," says David Knoll of the Southwire Company, an HTS cable manufacturer.

To take one example, serving congested urban environments as demand grows inexorably is a utility priority. Beginning in
2003, the DOE's Office of Electricity Delivery and Energy Reliability (DOE-OE) has sponsored demonstration projects at utility substations with costs split roughly 50-50 between DOE-OE and industry. Based on ac HTS cables with typical lengths of a few hundred meters, these projects demonstrated the ability to add capacity by simply replacing copper with superconducting cables in existing utility conduits, thus avoiding the expensive and daunting prospect of digging up the streets to install new ones. Though some feel it was premature, DOEOE deemed these so successful that it ceased supporting new efforts after 2009.

Nonetheless, the importance of continued government support at this stage of HTS development is well illustrated in Asia. The Korean Electric Power Corporation (KEPCO), 51\% percent government-owned, has a particularly ambitious plan for HTS in its grid and has recently installed a distribution cable at its I'cheon substation. Construction of a power substation in Baiyin, China's Gansu province, is supported by the Chinese Academy of Sciences and the State-owned Assets Supervision and Administration Commission of Baiyin City.

What can motivate US utilities to take up where DOE left off? Unfortunately, said Joseph Minervini of the Massachusetts Institute of Technology, "there are no killer apps to do the job." Syed Ahmed of Southern California Edison says that exploiting the benefits of HTS over the next decade is most likely to start with niche projects to build a technology foundation while gradually expanding markets and growing the manufacturing capacity to supply them. Minervini added that "microgrids" for isolated military bases and large urban data centers may provide another entrée by avoiding the need for investment by risk-averse utilities.

HTS fault-current limiters (FCLs) fit Ahmed's scenario nicely, as demonstrated in Europe. The Swedish utility Vattenfall has installed in Boxberg, Germany, an FCL made by the French company Nexans. These devices prevent high currents (fault currents) generated by disturbances in the grid from causing outages, but in the 21 st century, they must be faster acting and higher capacity to maintain the reliability and security of the network. In essence, HTS do this by rapidly transitioning to the normal, non-superconducting state when the current exceeds the material's critical current.

Off-shore wind energy may emerge as a renewable-energy application for HTS. Superconducting generators can be more powerful and much smaller than conventional devices, said Alex Malozemoff of AMSC, who foresees that HTS will permit the relatively compact, high-power wind turbines that can make off-shore energy affordable. Though HTS-based superconducting magnetic energy storage (SMES) is farther from commercial deployment, Qiang Li of Brookhaven National Laboratory said that the fast response and high efficiency of HTS-based SMES may make it a contender for the storage technology needed to complement intermittent sources like solar and wind farms.

Please visit 10.1557/mrs.2012.205 for a supplementary table on selected high-temperature superconductor utility projects. $\square$ 